\title{
Applied petrochemical research: final issue
}

\author{
Hamid A. Al-Megren ${ }^{1} \cdot$ Arno de Klerk $^{2}$
}

Published online: 3 November 2021

(c) The Author(s) 2021

\section{Introduction}

The Applied Petrochemical Research (APR) journal was setup 10 years ago by collaboration between Springer and King Abdulaziz City for Science and Technology (KACST), Saudi Arabia. The APR journal aims to help all aspects of the petrochemical industries by publishing original applied research focusing on new and smart technologies. Over 10 years, the journal published 11 volumes that included 271 articles.

In the final issue of the journal Applied Petrochemical Research, it is time for reflection. In the editorial that inaugurated the journal [1], it was explained that petrochemicals accounted for $6 \%$ of global energy consumption. There was sufficient justification to create a forum for research of an applied nature in this large human endeavor. It is an active and vibrant industry, with many technology offerings [2].

Why is it then that this journal is coming to its final issue?

In an attempt to answer this question, a good place to start is to look at the nature and origin of the work that was published in this journal. The original intent of the journal was to make it easier for scientists and engineers working in industry to publish applied studies. At the same time the journal welcomed applied research contributions dealing with petrochemicals from academia.

\section{Nature and origin of contributions}

The papers that were published were categorized based on their content and the origin of the contribution. To base the comparison on a comparable number of papers, the papers that were published in the first three years (2012-2014) were compared with those published in 2019-2020, when

\footnotetext{
Arno de Klerk

deklerk@ualberta.ca

KACST, Riyadh, Saudi Arabia

2 University of Alberta, Edmonton, Canada
}

a decision about the fate of the journal had to be made (Table 1).

The classification shown in Table 1 is somewhat subjective, particularly when it comes to papers that could be classified under more than one heading. Many contributions dealt with catalysts and catalysis. When the catalytic material was the main topic of investigation, then it was considered "catalysis science", but when the catalyst was part of an investigation that focused on the conversion or process, then it was classified under the heading best representing the topic of the conversion or process.

In most cases some link to petrochemicals research or some relevance to petrochemicals was explained. For example, when a contribution dealt with fluid catalytic cracking, the alkenes and aromatics are potential feed materials for petrochemicals. Papers were only classified as a paper dealing with petrochemicals when the primary objective was the petrochemicals. That should have been clear from the research that was presented and the reason for the study. For example, if a paper addressed a specific practical problem in a petrochemical process, then it was clearly a paper dealing with petrochemical research.

There was little change in the percentage of papers dealing specifically with petrochemical research, $23 \%$ in the first period, and $20 \%$ in the last period. Considering the title of the journal and its aim, it meant that the bulk of the papers that appeared in the journal were not primarily concerned with petrochemical research. The journal therefore failed to attract contributions from the community it was created to serve.

The change in the authorship of papers reflected a decreasing contribution from industry, $11 \%$ in the first period, and 6\% in the last period. At the same time there was an increase in the contributions from national research establishments, which often are research establishments that were created to support industry. Arguably, the journal became more successful at collectively attracting applied contributions with direct industrial relevance.

It was heartening that the collective contributions from industry and national research establishments came from

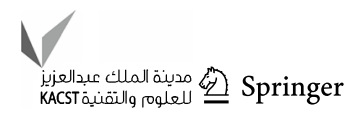


Table 1 Classification of papers in the journal based on topic and origin of the contribution

\begin{tabular}{lll}
\hline Description & \multicolumn{2}{l}{ Distribution (\%) } \\
\cline { 2 - 3 } & $2012-2014$ & $2019-2020$ \\
\hline Topic of paper & 23 & 20 \\
Petrochemical processes & 16 & 26 \\
Oil use/conversion $^{\mathrm{a}}$ & 10 & 6 \\
Oil additives/surfactants & 19 & 3 \\
Syngas manufacturing/conversion $^{\text {Catalysis science }}{ }^{\mathrm{b}}$ & 32 & 31 \\
Separations $^{\mathrm{b}}$ & 0 & 14 \\
Origin of paper $^{\mathrm{c}}$ & & \\
Industry $^{\text {National research establishments }}$ & 10 & 6 \\
Academic (universities) & 79 & 27 \\
\hline
\end{tabular}

${ }^{a}$ Includes papers dealing with oil characterization

${ }^{b}$ Focus was on the catalyst or the separation science, not the product or process

${ }^{c}$ When authors came from more than one of the categories, equal fractions were used

a wide selection of countries. For the periods covered in Table 1, the countries represented were Azerbaijan, Canada, China, Egypt, India, Mexico, Russia, Saudi Arabia, United Kingdom, and Venezuela. Several instances were noted where a healthy collaboration between industry, national research establishments and academia was clear.

\section{Final words and farewell}

The journal served a wide community. The generous sponsorship over ten years by the King Abdulaziz City of Science and Technology (KACST) in Saudi Arabia made this journal possible. It is with much gratitude that all the papers remain for wide dissemination as open access contributions through this sponsorship. We would like to thank KACST for their generous support, and also thank the authors, the reviewers, the board members, and the Springer members who worked closely with us in trying to make the APR journal a success.

Open Access This article is licensed under a Creative Commons Attribution 4.0 International License, which permits use, sharing, adaptation, distribution and reproduction in any medium or format, as long as you give appropriate credit to the original author(s) and the source, provide a link to the Creative Commons licence, and indicate if changes were made. The images or other third party material in this article are included in the article's Creative Commons licence, unless indicated otherwise in a credit line to the material. If material is not included in the article's Creative Commons licence and your intended use is not permitted by statutory regulation or exceeds the permitted use, you will need to obtain permission directly from the copyright holder. To view a copy of this licence, visit http://creativecommons.org/licenses/by/4.0/.

\section{References}

1. De Klerk A, Al-Khowaiter S (2012) Research for industry. Appl Petrochem Res 1:1-2

2. Meyers RA (ed) (2019) Handbook of petrochemicals production processes, 2nd edn. McGraw-Hill, New York

Publisher's Note Springer Nature remains neutral with regard to jurisdictional claims in published maps and institutional affiliations. 